\title{
COVID-19: general overview, pharmacological options and ventilatory support strategies
}

\author{
Francesco Menzella, ${ }^{1}$ Andrea Matucci, ${ }^{2}$ Alessandra Vultaggio, ${ }^{2}$ Chiara Barbieri, ${ }^{1}$ Mirella Biava,${ }^{3}$ Chiara Scelfo, ${ }^{1}$ \\ Matteo Fontana, ${ }^{1}$ Nicola Cosimo Facciolongo ${ }^{1}$ \\ ${ }^{1}$ Department of Medical Specialties, Pneumology Unit, Arcispedale Santa Maria Nuova, Azienda USL di Reggio Emilia- \\ IRCCS, Reggio Emilia \\ ${ }^{2}$ Immunoallergology Unit, Azienda Ospedaliero-Universitaria Careggi, Florence \\ ${ }^{3}$ University of Rome "La Sapienza”, Rome, Italy
}

The novel coronavirus called "Severe Acute Respiratory Syndrome Coronavirus 2" (SARS-CoV-2) caused an outbreak in December 2019, starting from the Chinese city of Wuhan, in the Hubei province, and rapidly spreading to the rest of the world. Consequently, the World Health Organization (WHO) declared that the coronavirus disease of 2019 (COVID-19) can be characterized as a pandemic. During COVID-19 several immunological alterations have been observed: in plasma of severe patients, inflammatory cytokines are at a much higher concentration ("cytokine storm"). These aspects are associated with pulmonary inflammation and parenchymal infiltrates with an extensive lung tissue damage in COVID-19 patients. To date, clinical evidence and guidelines based on reliable data and randomized clinical trials (RCTs) for the treatment of COVID-19 are lacking. In the absence of definitive management protocols, many treatments are currently being evaluated worldwide. Some of these options were soon abandoned due to ineffectiveness, while others showed promising results. As for ventilatory strategies, at the moment there are still no consistent data published about the different approaches and how they may influence disease progression. What will probably represent the real solution to this pandemic is the identification of a safe and effective vaccine, for which enormous efforts and investments are being put in place. This review will summarize the state-of-the-art of COVID-19 current treatment options and those potentially available in the future, as well as high flow oxygen therapy and non-invasive mechanical ventilation approaches.

Key words: Coronavirus; COVID-19; pneumonia; severe acute respiratory syndrome; pharmacologic treatment; respiratory failure; non-invasive ventilation.

Correspondence: Francesco Menzella, Department of Medical Specialties, Pneumology Unit, Azienda USL di Reggio EmiliaIRCCS, Viale Amendola 2, 42122 Reggio Emilia, Italy. E-mail: francesco.menzella@ausl.re.it

Contributions: FM, conceptualization, writing, original draft preparation, supervision; AM, CB, CS, writing, editing; AV, writing, original draft preparation; $\mathrm{MB}$, literature search, editing, writing; $\mathrm{MF}$, writing, reviewing and editing; $\mathrm{NCF}$, supervision, coordination and editing.

Conflict of interest: The authors have no competing interests.

Funding: This research did not receive any specific grant from funding agencies in the public, commercial, or not-for-profit sectors. Availability of data and materials: Available from the corresponding author on reasonable request.

Ethics approval and consent to participate: Not applicable.

Consent for publication: Not applicable. 


\section{Introduction}

Many of the viruses belonging to the coronaviridae family primarily cause zoonotic infections in birds and mammals; however, in the past year, coronaviruses have shown the ability to infect humans, primarily targeting the respiratory system [1]. CoVs (family Coronaviridae) are enveloped viruses with a positive sense, single-stranded RNA genome. They have been divided into three groups: $\alpha-\mathrm{CoVs}, \beta-\mathrm{CoVs}$, and $\gamma-\mathrm{CoVs}$ [2-4]. The novel coronavirus called "severe acute respiratory syndrome coronavirus 2 " (SARS-CoV-2) belongs to the $\beta-\mathrm{CoV}$ group and is the causative agent of the outbreak started in December 2019, from the Chinese city of Wuhan, in the Hubei province, and rapidly spreading to the rest of the world. Consequently, the World Health Organization (WHO) declared that the coronavirus disease of 2019 (COVID-19) has become a pandemic. This is the first ever caused by a coronavirus [5]. Focusing on current recommendations for the treatment of mild and severe COVID-19 cases, a cocktail of therapies with questionable evidence of efficacy is suggested, whereas others are more promising [6]. In patients with severe respiratory failure, the use of non-invasive mechanical ventilation is still under debate, but the timing and criteria need to be better defined.

The aim of this review is to analyze the different approaches in treating COVID-19, with an overview of the therapeutic options, the non-invasive mechanical ventilation, and describe the potential benefits or harms of their use with a special focus on severe cases. To our knowledge, this is the first review that gives a general overview of the many aspects to be taken into consideration on both the therapeutical and ventilatory management of COVID-19 patients, as well as imaging features.

\section{Methods}

A search in the literature using validated keywords filters to select articles regarding SARS-CoV-2, COVID-19 and related treatments was conducted. A literature research on biomedical bib- liographic databases (PubMed and Embase) was carried out up to August $9^{\text {th }}, 2020$, and research papers, international guidelines, and meta-analyses were considered as well as articles published "ahead of print". In view of the lack of randomized clinical trials (RCTs), reviews, case reports and case series were also included. The following keywords were used: coronavirus, SARS-CoV-2 pneumonia, COVID-19, severe acute respiratory syndrome, inflammation, respiratory failure, antivirals, corticosteroids, biologics, anticoagulants, mechanical ventilation. Ongoing clinical trials were selected using the coronavirus infection disease search term on ClinicalTrials.gov and the new coronavirus pneumonia study index in the Chinese clinical trial registry [7].

\section{Pathogenesis and immunological features}

SARS-CoV-2 belongs to the coronaviridae family and two possible hypothesis could explain its origin: natural selection in an animal host before zoonotic transfer; and natural selection in humans following zoonotic transfer [8].

SARS-CoV-2 is characterized by the typical coronavirus structure with spike protein and other polyproteins (Figure 1) $[9,10]$. Thus, SARS-CoV-2 uses the same ACE2 (angiotensin-converting enzyme 2) cell receptor as SARS-CoV for the entry into the host cell [11].

The extracellular domain of ACE2, expressed on alveolar type 2 cells other than heart, kidney, gut and endothelial cells, has been identified as the receptor for the spike (s) protein of the SARSCoV-2 [12,13]. Viral entry leads in COVID-19 patients to diffuse alveolar damage with the formation of hyaline membranes, in addition to monocyte infiltration of air spaces and thickening of the alveolar wall (Figure 2). These alterations can be observed both in early and late phase of SARS-CoV-2 infection [14,15]. An evidence of endothelial damage and inflammation alterations mimicry of vasculitis has been found in critically ill patients with negative clinical outcome. Pathology examination showed moderate infiltration sustained by monocytes and lymphocytes within and

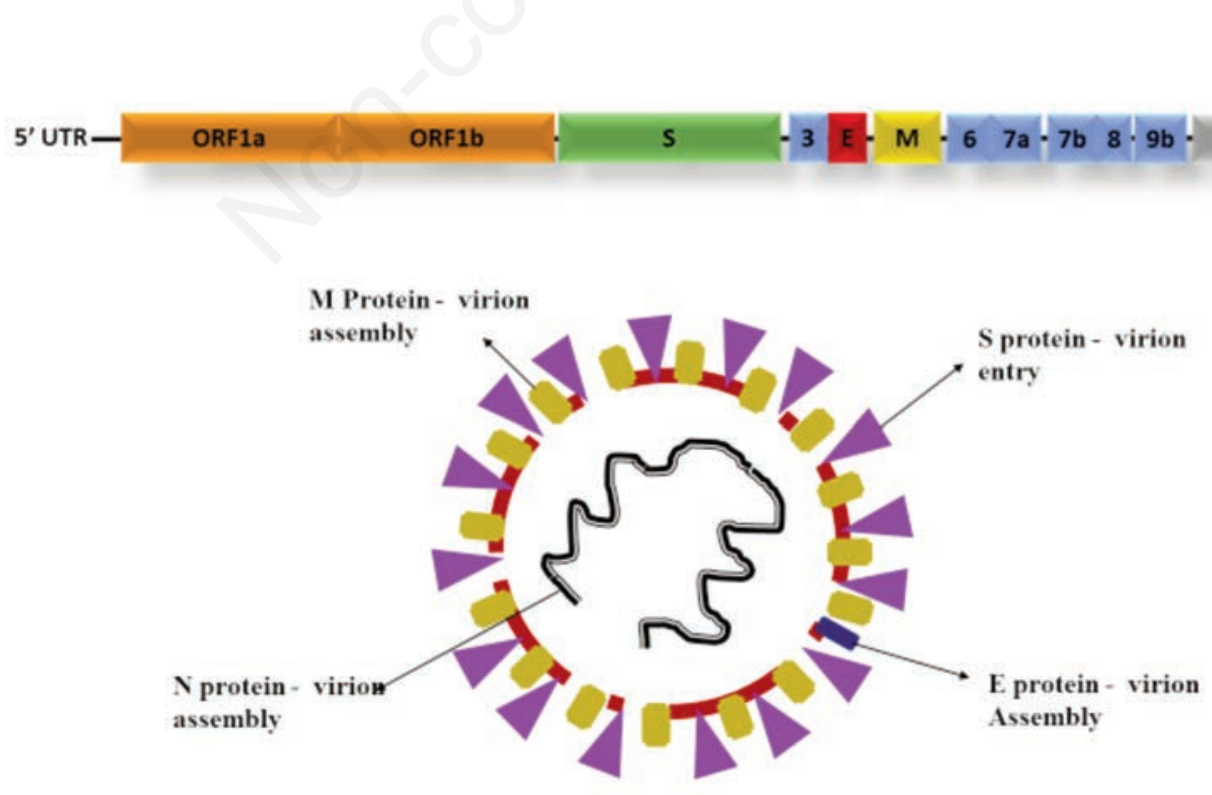

Figure 1. SARS-CoV-2 genome organization and structure. The SARS-CoV-2 genome comprises the 5'-untranslated region (5'- UTR), open reading frame (orf) $1 \mathrm{a} / \mathrm{b}$ (orange box) encoding non-structural proteins (nsp) for replication, structural proteins including spike (green box), envelop (red box), membrane (yellow box), and nucleocapsid (grey box) proteins, accessory proteins (blue boxes) such as orf $3,6,7 a, 7 b, 8$ and $9 b$ in the SARS-CoV-2 genome, and the 3'- untranslated region (3'-UTR). The 3' one-third of the genome encodes the structural proteins (S, E, M and N), which are essential for virus-cell-receptor binding and virion assembly. 
around walls of alveolar vessels that leads to occlusion and necrosis [14]. Endothelial cell involvement has been demonstrated in different organ (kidney, heart and nervous central system) [16]. The immune response to SARS-CoV-2, involving both innate and adaptive arms, is a key step during the infection. Several immunological hallmarks have been observed in patients during previous SARS-CoV infection such as a reduced antiviral response, characterized by low type I interferons (IFNs) production [17]. Among innate immune cells, natural killer (NK) cells exert a fundamental role in controlling acute viral infection mediated by direct cytotoxicity on infected cells [18]. Macrophages, that express ACE2, are important not only in the initial innate immune response towards SARS-CoV-2, but have also a crucial role as antigen-presenting cells (APCs) by interacting with $\mathrm{T}$ cells in the adaptive response $[19,20]$. Moreover, a specific antibody response induced by the virus and the production of specific anti-viral IgM, IgA, IgG antibodies has been demonstrated [21-23]. Secondary lymphoid organs appear atrophic, with necrosis area [24]. Accordingly, lymphocytopenia is one of the most prominent markers, including B and $\mathrm{T}$ cell populations and, among the latter, both helper and reg- ulatory T cells are affected [25]. Even though the immune response is crucial for controlling SARS-CoV-2 infection, dysregulated and excessive immune responses may cause immunopathology. In fact, inflammatory cytokines (IL-6, TNF- $\alpha$, IL-10, IL-2, IL-7, CXCL10, CCL2, CCL3) are higher in plasma of severe cases ("cytokine storm"), and are associated with pulmonary inflammation and extensive lung tissue damage in COVID-19 patients [26,27].

\section{Clinical and radiological characteristics}

The exact viral incubation period is not known. It is assumed to be between 2 and 14 days after exposure (median incubation period was 4 days after exposure). Most of those affected were aged between 35 and 58, with a predominance in men [28]. At the very early presentation, the more frequent symptoms are fever (at least $37.3^{\circ} \mathrm{C}$ ), fatigue, dry cough, myalgias, dyspnea [17], and other less common symptoms are headache, sore throat, rhinorrhea, conjunctivitis and gastrointestinal symptoms. Another characteristic symptom is anosmia, whose causes have recently been
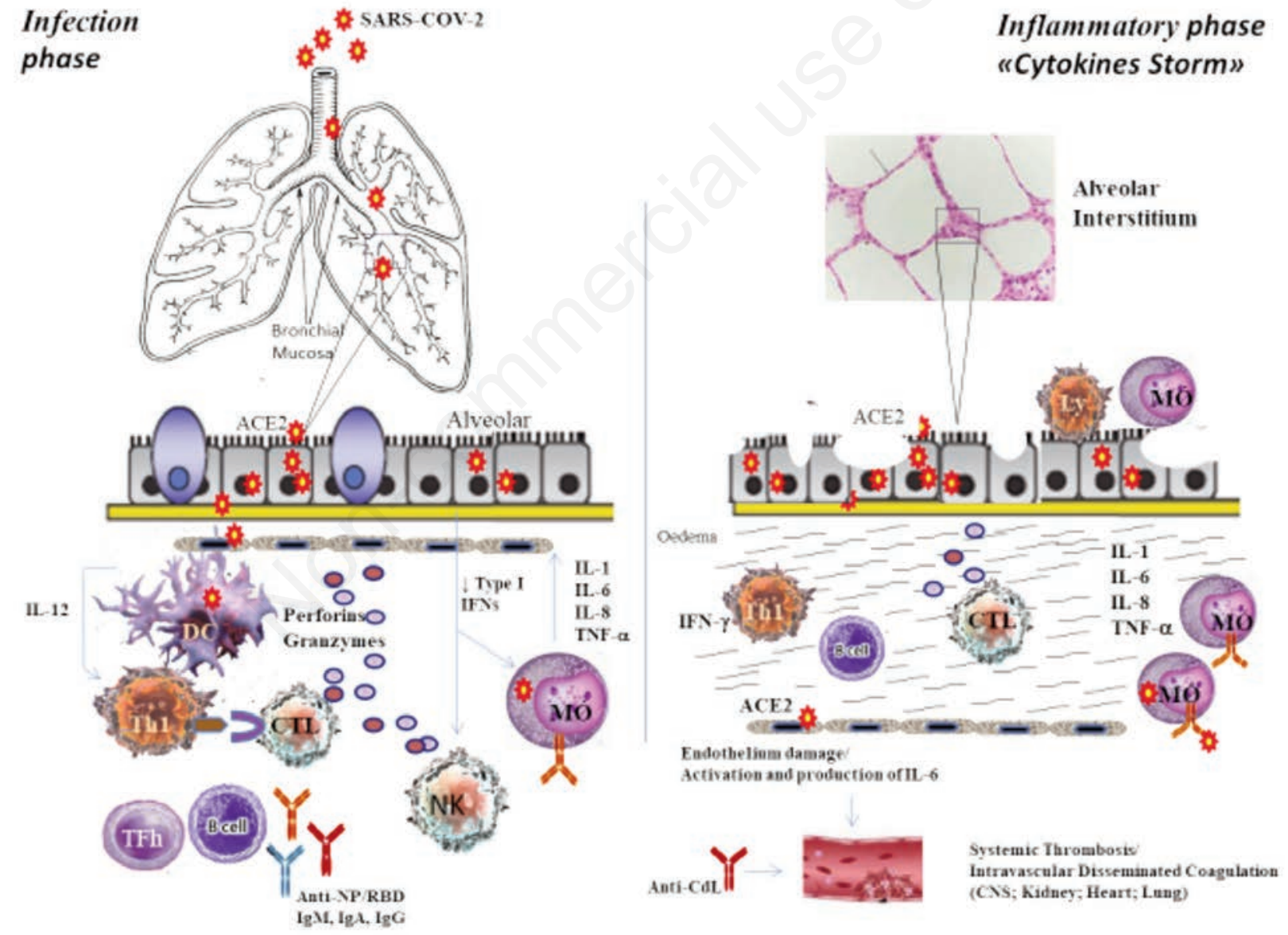

Figure 2. Pathogenic mechanisms of acute SARS-CoV-2 infection and hyperimmune activation (“cytokine storm"). SARS-CoV-2 virus uses angiotensin-converting enzyme-2 (ACE2) as its cellular receptor highly expressed by type II pneumocytes. A rapid innate immune response mediated by natural killer (NK) cells cytotoxic activity represents a first line of defence towards the virus. Infected dendritic cells (DCs) and macrophages (MǾ) initiate the adaptive immune response (Th1 cells differentiation) with a subsequent activation of CD8+ cytotoxic T lymphocytes (CTL) and recruitment of antibody secreting cells by follicular T helper cells (Tfh) leading to the production of IgM, IgA and IgG against viral nucleoprotein (NP) and surface spike protein receptor binding domain (RBD). SARS-CoV2 binding antibodies may participate in tissue damage by macrophage activation via $\mathrm{Fc} \gamma \mathrm{RI}$ (on the left). Deregulated and excessive immune response with secretion of large amount of cytokines (i.e. IL-1, IL-6, IL-8, TNF- $\alpha$ ), may cause inflammation and extensive lung tissue damage in COVID-19 patients. Thrombotic microangiopathy is favored by both endothelial activation and deregulation of immune response (production of pro-coagulant antibodies) (on the right). IL, interleukin; TNF, tumor necrosis factor. 
elucidated [18]. The virus infiltrates the brain, perhaps from the nose, and affects the olfactory centers (olfactory bulb and cortex), thereby reducing olfactory sensations. Another scenario is represented by the virus that infects the neurons of the olfactory receptors, leading them to death, and by the damage of the olfactory centers, thus reducing the olfactory sensations [29].

The spectrum of clinical manifestations seems to be wide, including asymptomatic infection, mild upper respiratory tract symptoms, mild and severe pneumonia with severe lower respiratory tract involvement, acute respiratory distress syndrome, sepsis and septic shock [30].

The severity of presentation appeared strictly related to age and the presence of coexisting illness (among the overall population, $24 \%$ have at least one comorbidity, e.g. hypertension, diabetes mellitus and obesity) [17]. According to the Diagnosis and Treatment Plan of COVID-19 suggested by National Health Commission of China [30], among Chinese cohorts of patients with confirmed infection most had mild illness (81\%), 14\% had severe illness, and only $5 \%$ had a critical disease (respiratory failure, shock, multi-organ dysfunction syndrome) $[31,32]$.

COVID-19 patients could also develop neurologic complications (e.g. macrovascular stroke, Guillain-Barrè syndrome), skin lesions (e.g. rashes, "covid toes"), acute kidney injury requiring dialysis. Severe illness is characterized by hypoxemia (arterial oxygen saturation $\leq 93 \%$ or respiratory rate $\geq 30$ breaths $/$ min or the ratio of arterial oxygen partial pressure to fractional inspired oxygen $\left.\left(\mathrm{PaO}_{2} / \mathrm{FiO}_{2}\right) \leq 300 \mathrm{mmHg}\right),>50 \%$ lung involvement on chest tomography. Overall fatality rate was between 2.3 to $5 \%$, with no deaths occurring in the population aged 9 or younger, nor mild or severe cases.

In clinical practice, the increase of C-reactive Protein (CRP), D-dimer, lactate dehydrogenase (LDH), liver enzymes, creatine phosphokinase (CPK), normal level of procalcitonin (PCT), blood glucose abnormalities associated with typical laboratory findings such as low white blood cell count (lymphopenia in $80 \%$, in particular CD4) and mild thrombocytopenia are often present [17]. The white blood cell count could be normal or high if there is a coexisting secondary infection (bacteremia or positive culture). The high PCR level and lymphopenia are associated with poor prognosis [17]. The presence of coagulation disorders has recently emerged as responsible for a large majority of deaths from COVID-19, due to disseminated intravascular coagulation (DIC) [33]. The risk of venous thromboembolism (VTE) in severe COVID-19 is increased and for these reasons some expert consensus in China recommended the use of anticoagulants (such as heparin) for the treatment for severe COVID-19 infections [32-34]. It has been demonstrated from lung organ dissections the presence of occlusion and microthrombosis formation in pulmonary small vessels of COVID-19 critical patients [35]. Another interesting potential risk factor recently described is the presence of antiphospholipid antibodies [27]. Radiological findings are crucial for suspecting SARS-CoV-2 infection. Chest $\mathrm{X}$ ray are not characteristic and usually could be normal at the initial phases of the disease. The most common features are mono or bilateral peripheral opacities [36]. The typical chest computed tomography (CT) features are: ground glass opacities (GGO), "paving stone-like", thickening of interlobular septa with small honeycomb-like with fuzzy edge, multiple or patchy opacities in both lungs and consolidations. Atypical manifestation includes several consolidations with pleural effusion or enlargement of mediastinal lymph nodes, nodules, extensive thickening of the bronchial wall or interlobular septa. The findings obtained on the chest tomography have a good correlation with the natural history of the disease. It is of notice that the GGO are usually due to thickening of the septa or exudation of fluid in alveolar cavity, due to acute lung injury which leads to diffuse alveolar damage.
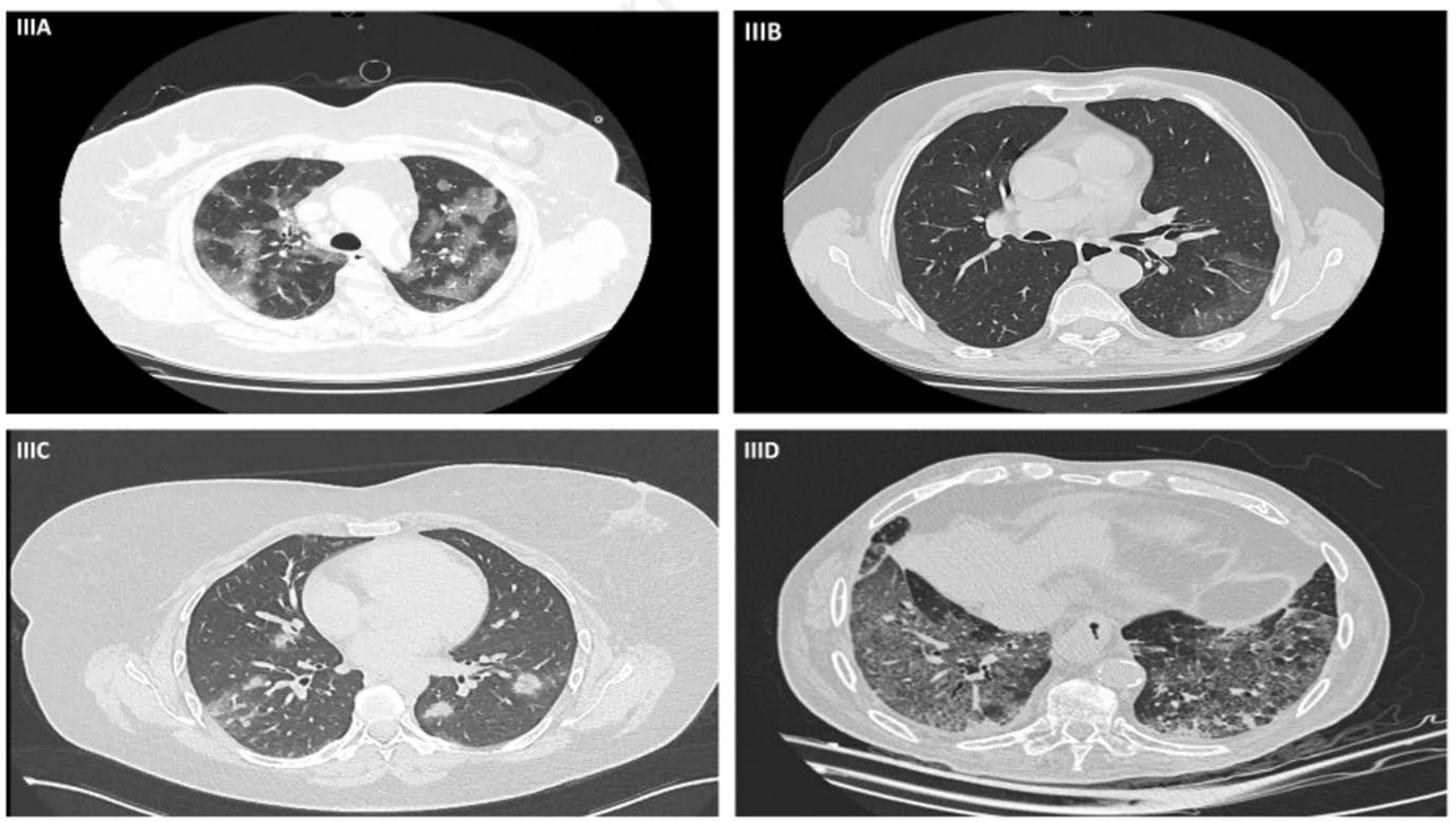

Figure 3. Ultra early and early stage of chest CT findings. Ultra early stage: A) Bilateral diffuse GGO; B) Small confined area of GGO. Early stage: C) GGO opacities, sometimes with round shape; 3D) GGO agglomerated or scattered patchy associated with thickening of interlobular septa. GGO, ground-glass opacity. 
In the "ultra-early stage" when patient is asymptomatic, the main imaging manifestations are often single or multiple GGO over consolidation and milder extension of disease on chest CT, like in the cohort of patients from the Cruise Ship "Diamond Princess" (Figure 3 IIA - IIIB) [37]. In this phase, it is difficult to have consolidation. In the "early stage" (1-3 days after clinical manifestations), the most frequent features are single or multiple ground glass opacities agglomerated or scattered patchy associated with thickening of interlobular septa grid-like or honeycomb-like (Figure 3 IIIC - IIID). In this stage, the vascular enlargement due to inflammation and congestion of alveolar septal capillary and/or microthrombosis is a typical aspect to be taken into consideration [37]. In the "progressive stage" (3-8 days after initial clinical manifestations), the findings usually include a rapidly involvement of the lungs with multi-lobe distribution and perilobular pattern at the upper lobes. Radiological features are GGO, crazy-paving and consolidation with air-bronchogram inside, due to vascular expansion and exudation in the interstitium and in the alveolar cavity. Moreover, the chest CT images could also mimic an organizing pneumonia (OP) and it's possible to identify the atoll sign or the reverse halo sign (Figure 4 IVA - IVB) $[38,39]$. In the "consolidation stage" (8-14 days after clinical manifestations), patchy consolidation becomes denser and the capillary congestion in the alveolar wall give the way to fibrous exudation of the alveolar cavity (Figure IVC - IVD). The consolidation appears more evident in the lower lobes. In the "dissipation stage" (2-3 weeks after the onset of clinical manifestation), chest CT images showed patchy consolidation, thickening of interlobular septa and distortion of bronchial wall. It may be possible to note a timing discrepancy between the clinical features and the chest CT in the case of a too early radiological follow up. Moreover, the differential diagnosis with other lung diseases may not be easy $[39,40]$.
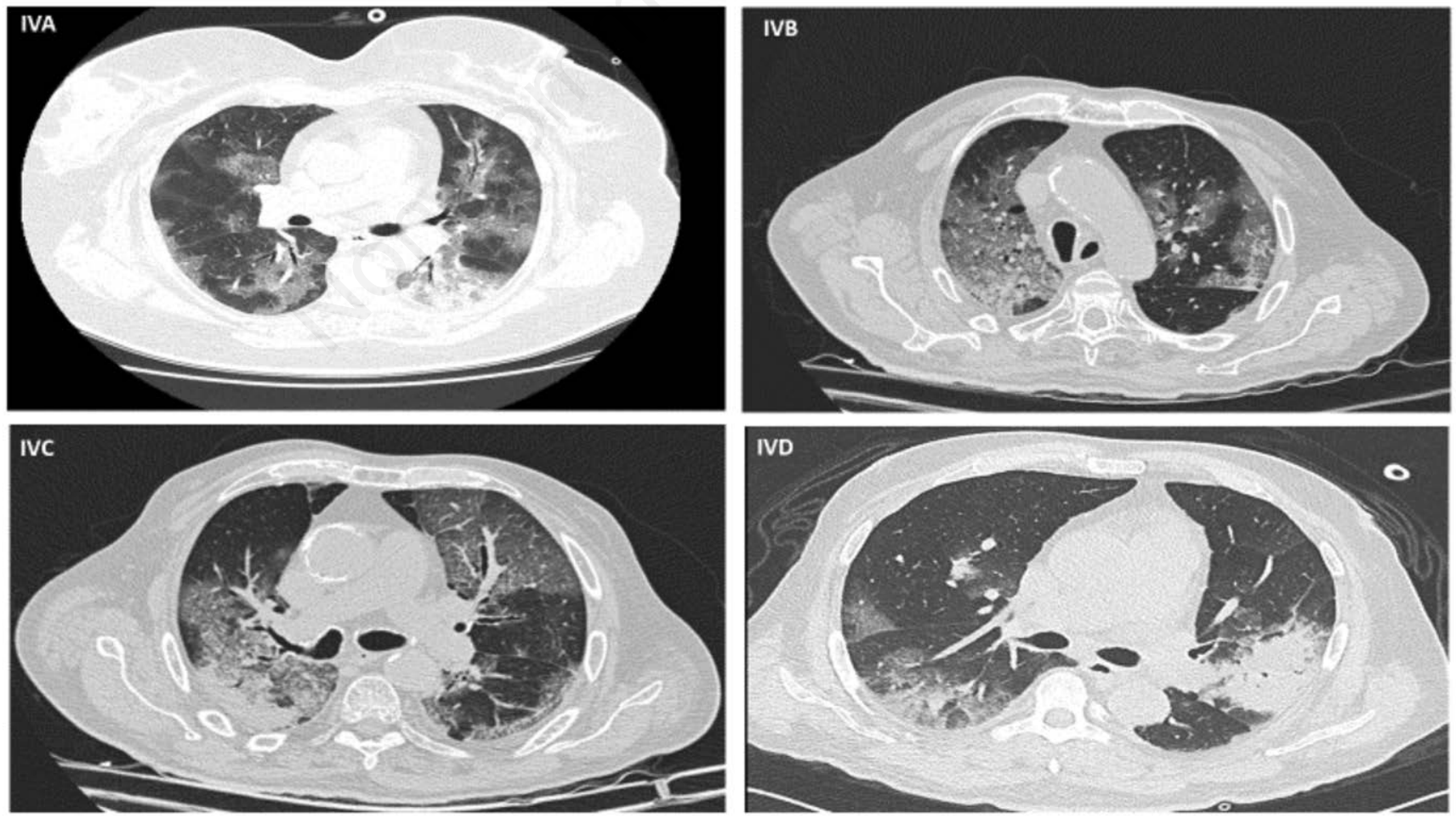

Figure 3. Progressive and consolidations stage of chest CT findings. Progressive stage: A) Multiple GGO and initial consolidation combined in varying proportions; B) Simultaneous finding of bronchial involvement (bronchial wall thickening, bronchiectasis) and illdefined centrilobular nodules due to alveolar filling. Consolidations stage: C,D) Multiple opacities tend to be distributed peripherally without craniocaudal predilection, but usually the lower lobes (costophrenic recesses, vertebral areas). 
Currently, remdesivir is experimented in China on mild to moderate (NCT04252664) and severe (NCT04257656) COVID-19 patients in order to test the real efficacy of this treatment. Under this point of view, it has been recently demonstrated that remdesivir's antiviral activity is rapidly effective when the virus enters Vero E6 cells, carrying out its antiviral mechanism as a nucleotide analogue $[42,49]$. At the moment, studies on remdesivir are registered, but only some of them are double-blind RCTs, whereas others are uncontrolled observational studies [49,50]. Specifically, preliminary trials on remdesivir carried out by the US National Institute of Allergy and Infectious Diseases (NIAID) showed a positive effect in reducing the time to recovery and decreasing mortality rate, even if this data was not statistically significant [51]. On the other hand, positive results were obtained by the most recent double-blind, randomized, placebo-controlled trial of intravenous remdesivir in adults who were hospitalized with Covid-19 and had evidence of lower respiratory tract infection. Patients were randomly assigned to receive either remdesivir $(200 \mathrm{mg}$ loading dose on day 1 , followed by $100 \mathrm{mg}$ daily for up to 9 additional days) or placebo for up to 10 days. Results showed that remdesivir was superior to placebo in shortening the time to recovery (median, 10 days, as compared with 15 days; rate ratio for recovery, $1.29 ; 95 \%$ confidence interval [CI], 1.12 to $1.49 ; \mathrm{p}<0.001)$ [52].

Notably, on opposite results lays the study coordinated by the WHO, which indicated that remdesivir, along with three other potential drug treatments for COVID-19, has "little or no effect" on death rates among hospitalized patients, as indicated by overall mortality, initiation of ventilation and duration of hospital stay [53]. The article is a preprint and has not been certified by peer review, the results should be further analyzed and discussed.

Even if the activity on SARS-CoV-2 is still to be proved, HIV protease inhibitor, such as lopinavir/ritonavir, were initially found to act on MERS-CoV and SARS-CoV and showed efficacy for SARS $[54,55]$; consequently, the combination was initially widely used for the treatment of SARS-CoV-2 infection, but it has showed uncertain results. The first randomized, open-label, controlled trial involving 199 hospitalized adult patients with SARS-CoV-2 infection and respiratory failure unfortunately showed no benefit with lopinavir / ritonavir compared to standard of care [56].

At the moment, data regarding oseltamivir efficacy in COVID19 are not available, even if this treatment has been applied for SARS-CoV-2 suspected and confirmed patients in China $[57,58]$.

\section{Chloroquine and hydroxychloroquine}

The chloroquine sulphate and phosphate salts are known as antimalarial drugs. Hydroxychloroquine has been applied as an antimalarial and also for the treatment of autoimmune diseases, such as lupus and rheumatoid arthritis. These drugs show a satisfactory safety profile with mild and transient side effects, if correctly dosed. Under this point of view, it should be noted that overdose or prolonged treatments may cause cardiomyopathies and QT prolongation [59]. Chloroquine has also been used for the treatment of chronic viral diseases [60,61]. Wang and colleagues assessed its efficacy in vitro and evaluated it as highly effective in controlling SARS-CoV-2 replication [42]. It has been noted that chloroquine interferes with the ability of SARS-CoV-2 to acidify lysosomes and inhibits cathepsins, allowing the cleavage of the spike protein of SARS-CoV-2 [62]. According to a recent study, chloroquine phosphate can be superior to control in the treatment of COVID-19 pneumonia, acting on clinical and imaging aspects and reducing shortening the course of the disease [63].

A non-randomized clinical trial based on a small group of patients showed a significant improvement in viral clearance. It has also been proved that this drug combined with azithromycin can reduce the viral load more than hydroxychloroquine monotherapy [64]. Another study with few patients hospitalized for severe SARS-CoV-2 infection did not show strong antiviral activity or clinical efficacy of the combination of hydroxychloroquine and azithromycin [65]. This difference between the outcome of the two said studies underlines the importance to carry out RCTs to assess the efficacy of these drugs in the treatment of COVID-19. An open-label non-randomized clinical trial showed high efficacy of hydroxychloroquine against COVID-19 [66], while another study showed no evidence of rapid antiviral clearance or clinical benefit with the combination of hydroxychloroquine and azithromycin in severely infected patients from COVID-19 [67]. Furthermore, from a multicenter study based on hydroxychloroquine with or without macrolides not only did not emerge the efficacy of this molecule but a higher risk of de novo ventricular arrhythmia during hospitalization. Anyway, this heavily-criticized study was not found reliable in the view of its accuracy on the analysis of data and the results were therefore retracted [68]. To conclude, it emerged from the published data that currently there is no evidence about the efficacy of chloroquine on COVID-19. Confirming this statement are the results of the RECOVERY (Randomised Evaluation of COVid-19 thERapY) trial, which enrolled over 11,000 patients from 175 hospitals in the UK. Preliminary data from this large RCT unfortunately highlighted a lack of benefits of hydroxychloroquine in hospitalized patients with COVID-19. Considering these negative results, it was decided to stop patients' enrollment [69].

\section{Corticosteroids}

Corticosteroids showed conflicting data of efficacy, and the setting of application is not well defined. In the lack of unambiguous data, their use is not recommended by the WHO interim guidance on COVID-19 management [30]. Moreover, version 7 of the National Health Commission of China guidelines pointed out that corticosteroids should be used carefully in the case of SARS-CoV2 patients [32]. Recently, a study involving patients with acute respiratory distress syndrome (ARDS) due to COVID-19 showed significant results in increasing survival rate in patients treated with methylprednisolone $(\mathrm{p}=0.003)$ [70].

A study based on critically ill patients affected by SARS-CoV1 showed that the correct treatment with corticosteroids significantly reduces hospitalization mortality and duration [71], without increasing superinfections and important complications. Another study involving ICU patients treated with corticosteroids did not reach significant conclusions because of the sample size [26]. It can be argued that corticosteroids combined with both invasive and non-invasive mechanical ventilation can help preventing progression to ARDS, with particular impact on critically ill patients [14]. The Chinese Thoracic Society released an expert consensus statement on the use of corticosteroids for the treatment of COVID-19 pneumonia [72]. This document pointed out that corticosteroids should be used carefully in severe patients and that the dosage should be low to moderate $(\leq 0 \cdot 5-1 \mathrm{mg} / \mathrm{kg}$ per day of methylprednisolone or equivalent) and limited to a short period ( $\leq 7$ days). A very recent study has shown that corticosteroid therapy does not appear to reduce hospital mortality and is not associated with delayed viral clearance. At the same time, it could alleviate the inflammatory aspect and improve symptoms [73]. According to other authors RCTs are necessary to get more details about the treatment with these important drugs [74]. The preliminary results of the RECOVERY study are very interesting. In this RCT a total of 2,104 patients were randomized to dexamethasone $6 \mathrm{mg}$ once 
daily (orally or intravenously) for ten days and compared with 4,321 patients randomized to usual care alone [75]. The data show a one-third reduction in deaths in ventilated patients $(\mathrm{p}=0.0003)$ and one-fifth in patients on oxygen therapy $(\mathrm{p}=0.0021)$, while no benefit was found for less severe patients among those patients which did not require respiratory support $(p=0.14)$ [75].

\section{Biologics}

Tocilizumab (TCZ), or atlizumab, is a humanised IgG1k monoclonal antibody $(\mathrm{mAb})$ that targets the soluble or membrane interleukin (IL)-6 receptors (Sil-6R and Mil-6R). This treatment has been applied to autoimmune diseases such as rheumatoid arthritis (RA) or large vessels vasculitis [76]. Also in this case, similar to SARS-CoV-2 infection, the serum levels of inflammatory mediators are proportional to the severity of the disease in the specific context [26]. In severe patients, strong immunological responses can cause cytokine storms and be the origin of several damages to multiple organs. Higher IL-6 levels can also be an evidence of clinical worsening and other severe damages. In this framework TCZ can act on two inflammatory factors, IL-6 and GM-CSF and therefore can have a role in decreasing the inflammation. Recently was made a multicenter RCT aiming at assessing the efficacy and safety of TCZ with regard to moderate patients at high risk of evolution towards serious and critical illness (ChiCTR2000029765). Relevant results are not available yet, but they are expected to be positive in patients with high IL-6 levels. In a retrospective study of 100 patients with severe respiratory failure due to COVID-19 pneumonia and treated with TCZ, 77\% of cases showed a favorable clinical response, associated with significant clinical improvement [77]. Another recent retrospective study showed that TCZ treatment may be effective in COVID-19 patients with severe respiratory impairment receiving non-invasive ventilation (NIV) [78].

Sarilumab is a fully human $\operatorname{IgG} 1 \mathrm{mAb}$ targeting soluble and membrane IL-6 receptors, inhibiting IL-6-mediated signal transduction mediated by these receptors $[79,80]$. Similarly to TCZ, the use of sarilumab has recently been applied to treat patients with severe forms of COVID-19. The results of five ongoing RCT (ClinicalTrials.gov Identifiers: NCT04315298, NCT04327388, NCT04324073, NCT04322773, NCT04321993) will be especially important.

Canakinumab is a fully human anti-IL- $1 \beta$ IgG1 mAb approved for the treatment of periodic autoinflammatory fever, Still's disease, and gouty arthritis [81]. A phase III RCT has recently started to study canakinumab in patients with COVID-19 pneumonia. The CAN-COVID study will evaluate the effectiveness of using canakinumab to counteract the cytokine storm (ClinicalTrials.gov Identifier: NCT04362813).

\section{Convalescent plasma}

In other severe viral infections, the plasma of recovered patients was found useful in treating patients, thanks to its high content of neutralizing antibodies [82]. Thus, based on the increasing knowledge of antibody response in viral infections and in the current pandemic, the FDA has recently given approval for the initiation of clinical trials for the evaluation of the efficacy of convalescent plasma treatment in COVID-19 patients. Unfortunately, the recently published RCT in critically ill COVID-19 patients resulted in little or no improvement and the duration of disease was not affected by its addition in standard treatment of COVID-19 [83]. A proof of concept multicenter single-arm study on 46 severe COVID-19 patients treated with hyperimmune plasma showed promising benefits in terms of mortality, reduction in inflammatory indices and respiratory failure. Unfortunately, serious adverse events occurred in 4 patients, one of which was a "transfusionrelated acute lung injury" (TRALI) [84].

Therefore, while promising, convalescent plasma remains experimental and has not proven effective yet. Moreover, many questions remain regarding the accuracy and predictive value of antibody testing of donors and patients, optimal donor selection, and optimal timing and selection of patient most likely to benefit. Until these questions are answered, convalescent plasma should ideally be used in the context of well-designed randomized clinical trials [85].

\section{Invasive and non-invasive ventilation}

Despite the severity of respiratory failure and the massive need for mechanical ventilation in COVID-19 patients, there are not consistent data published about key ventilation items, as the role of invasive and non-invasive ventilation, positive end-expiratory pressure (PEEP) titration, prone positioning and in choosing tidal volumes.

The few data available suggest that the pathophysiology of COVID-19 patients might be very different and this may lead to a different ventilatory management. For example, a recent report suggested that median compliance of these patients is significantly higher than in ARDS classical patients, given the same level of respiratory failure [86]. This could explain the large mismatch observed between oxygenation level and dyspnea; despite the low oxygen level, the work of breathing in these patients is not so dramatically increased. This may be linked to a relatively conserved lung compliance, at least in some patients.

In a recent article, the authors hypothesized existence of two major phenotypes of COVID-19 pneumonia [87]. The first one (called "type L", due to low lung elastance), that is present at the time of diagnosis, has quite normal compliance, low ventilation-toperfusion (VA/Q) ratio, only GGO at CT scan and low amount of non-aerated lung.

Afterwards, some patients may worsen, showing another phenotype (called "type H", due to high lung elastance), much more similar to classical ARDS, showing decreased lung compliance (due to increased edema), high right-to-left shunt, high lung weight, and increased amount of non-aerated tissue (associated, as in severe ARDS, with increased recruitability).

The type H pattern, $20-30 \%$ of patients in their series, fully fits the classical severe ARDS criteria: hypoxemia, bilateral infiltrates, decreased the respiratory system compliance, increased lung weight and potential for recruitment, due to high amount of non-aerated lung [83]. In a very recent retrospective study, the authors demonstrated that compliance and lung weight estimation are not correlated in patients with COVID-19-related ARDS. Most patients cannot be classified as "H" or "L" subphenotype as postulated by the authors, rather presenting mixed characteristics [88]. These considerations open up a wide number of very interesting and unanswered questions, as the role of non-invasive positive pressure ventilation (NPPV) and continuous positive airway pressure (CPAP). These methods emerged because they allow the treatment of a large number of patients at the same time and can also be applied outside of the intensive care unit (ICU). No data is available showing if there is any difference between CPAP and NPPV in survival or intubation rate. Patients undergoing CPAP or NPPV must be carefully monitored to understand if they are worsening. In addition to obvious clinical parameters, one very interesting and useful tool would be monitoring esophageal pressure (that is an indirect measure for pleural pressure). This has shown to be a 
predictor for NIV failure in non-COVID patients with de novo respiratory failure [89]. The magnitude of inspiratory pleural pressures swings may determine the transition from $\mathrm{L}$ phenotype to $\mathrm{H}$ phenotype. Managing NPPV in COVID-19 patients requires careful monitoring and close attention also to supportive therapy. Nutritional support is a key strategy to avoid NPPV interruption and to provide adequate energy and protein requirements. Early enteral nutrition has been shown to decrease complications and hospital length of stay and improve the prognosis at discharge in nonCOVID critically ill patients [90].

Sedation or algosedation in NPPV, very useful to guarantee tolerance to a long-lasting ventilation, is under debate, with low quality of evidence for drugs [91] (opioids, benzodiazepines, dexmedetomidine); despite this, many centres applied some kind of sedation in NPPV patients [92,93]. Another open question is whether the delay of intubation affects the prognosis. It seems to be reasonable; however, no data are available. Even JAMA's guideline points out that early intubation in this setting is a 'best practice statement'. Given the wide number of patients that need ventilation in these days, quite every patient underwent a NPPV trial before intubation. When data will be available, it will be very interesting to look at the duration of NPPV in patients that were intubated and to check whether there is a correlation between longer NPPV duration before intubation and survival or duration of invasive ventilation. In addition, there are no data about the burden of selfinduced lung injury (SILI) in these patients, when in spontaneous breathing or in NPPV. When esophageal pressure swings increase from 5 to $10 \mathrm{cmH}_{2} \mathrm{O}$ - which are generally well tolerated - to above $15 \mathrm{cmH}_{2} \mathrm{O}$, the risk of lung injury increases and therefore intubation should be performed as soon as possible [85]. Unluckily, there are no data about the swings of esophageal pressure in these patients, due to the many problems connected to asses a huge number of patients from a pathophysiological point of view in this pandemic context.

Regarding the role of the prone positioning, empirical experiences suggest that this method can increase dramatically oxygen saturation, even in standard oxygen or NPPV patient. The rapidity of oxygenation increase can suggest that the positioning of the patient may improve oxygenation by a redistribution of blood flow into the lung, reducing V/Q mismatch. In a single centre Chinese study, 12 patients showed an increased lung recruitability and increase of the ratio of arterial oxygen partial pressure to fractional inspired oxygen $\left(\mathrm{PaO}_{2} / \mathrm{FiO}_{2}\right)$, when receiving prone positioning [52]. Based on the limited data available it is reasonable to assume that the prone position in ventilated and non-ventilated conscious patients with COVID-19 infection may improve shortterm oxygenation and postpone or prevent the need for endotracheal intubation [94]. It is not yet clear what it is the best PEEP for these patients. The massive presence of GGO in chest CT scans of COVID-19 patients might mean that there is a lot of recoverable lung, even if no conclusive information is available. In addition, during NPPV, there is no direct measure for choosing best PEEP. There may be some information by lung ultrasonography, useful to detect the endpoint of lung recruitment and the best PEEP levels [95]. On the contrary, during invasive ventilation, the best PEEP can be chosen by measuring compliance at different PEEP levels.

Regarding protective ventilation, even though there is no specific data available on COVID-19 patients, JAMA guidelines suggest the use of low tidal volume ventilation $(4-8 \mathrm{ml} / \mathrm{kg}$ of predicted body weight) over higher tidal volumes $(>8 \mathrm{ml} / \mathrm{kg})$ [6].Targeting plateau pressures of $<30 \quad \mathrm{~cm} \mathrm{H}_{2} \mathrm{O}$ (strong recommendation, moderate quality of evidence) is recommended; for selected patients, if it is not possible to maintain a protective ventilation, extra-corporeal membrane oxygenation (ECMO) support should be considered [95]. As for now, anecdotal efficacy data exist in this regard, but prospective studies are currently lacking
[97]. A recent large observational study involving 670 patients admitted to Pulmonology Units confirmed that the application of NIV outside the ICUs is feasible and associated with favourable outcomes [98]. However, it was associated with a risk of healthcare professionals' contamination, which must therefore be taken into great consideration.

\section{High-flow oxygen}

High flow nasal cannula (HFNC) systems were widely used during the COVID-19 pandemic. These are also able to provide heating and humidification, improving patient tolerance and comfort. The high flow rates above all have the advantage of increasing the delivered $\mathrm{FiO}_{2}$ and are able to at least partially eliminate carbon dioxide in the dead space, improving the efficiency of oxygen delivery. The higher flow translates into PEEP, the quantity of which varies between $0.35-0.69 \mathrm{~cm}$ of water for every $10 \mathrm{l} / \mathrm{min}$ of increased flow [99].

A meta-analysis that included 9 RCTs and 2,093 patients found that HFNC in patients with acute hypoxemic respiratory failure (ARF) can reduce the need for tracheal intubation without affecting mortality [100].

There are currently no RCTs available on the efficacy of HFNC in patients with COVID-19 ARF or ARDS. Observational studies or case reports have been published that support the possible application of HFNC also in this area, but prospective trials and studies with much wider cases are needed [100,101].

Summing up, no data on the best ventilation strategy in COVID19 is available. RCTs will provide important knowledge, but it will take time. At the moment, the best of our current clinical practice is probably the optimal solution. In this dramatic context, information sharing is also fundamental.

\section{Future directions}

The research to identify one or more drugs that are truly effective in treating COVID-19 is massive and supported by huge investments. Numerous studies are underway on more or less promising drugs with different molecular targets. It would be impossible to report all the studies in progress, therefore we will only refer to those with the most interesting implications.

\section{Natural killer cells}

NK cells are important immune cells needed for defence against cells infected with microbes or in defence against cancer [102]. A trial has recently been announced to extend the use of CYNK-001, a ready-to-use allogeneic NK cell therapy, derived from umbilical cord blood, to the treatment of new SARS-CoV-2 infections [103]. NK cell therapy enhancing host immunity could prove to be a very promising strategy for treating COVID-19 pneumonia.

\section{Mesenchymal stem cells}

Mesenchymal stem cells (MSCs) are known to have strong antiinflammatory and immunomodulatory effects. In the past, some authors have shown that MSC treatment can improve acute / chronic lung injury and ARDS by suppressing the infiltration of immune cells into lung tissues and the secretion of pro-inflammatory cytokines, while reducing pulmonary fibrosis and improving tissue 
repair [104-108]. Consequently, MSCs could be a promising therapeutic option in the treatment of cytokine storm, ARDS, and acute lung injury in patients with severe COVID-19.

\section{Nanomedicines}

The RECOVERY study demonstrated the efficacy of dexamethasone in critically ill patients with COVID-19 [75]. At the preclinical level, some diseases have been successfully already treated with dexamethasone nanomedicine, including rheumatoid arthritis, inflammatory bowel disease, multiple sclerosis, liver fibrosis and cancer [109-112]. The hypothesis that dexamethasone nanomedicines are a potential treatment option for COVID-19 is based on known evidence that nanoparticles selectively accumulate in macrophages, upon intravenous administration as well as upon inhalation. Dexamethasone-based nanomedicines do have though a high level of complexity also in terms of composition and manufacture, and will need to be clinically tested prior to availability. In some studies dexamethasone nanomedicines have allowed greater efficacy of the drug in terms of improved survival of critical patients, so they could prove to be an important weapon in the fight against COVID-19 [113].

\section{Conclusions}

Unfortunately, at the present time the management of COVID19 has more doubts than certainties. The standard of care was initially represented by antiviral drugs such as remdesivir, chloroquine or lopinavir / ritonavir, even if the evidence is not satisfactory. Remdesivir was the most promising antiviral drug. However, the two recent RCTs with opposite results pose a huge uncertainty on its efficacy and careful examination of RCTs results should be undertaken. Nevertheless, there are still many open questions we have to answer about pathogenesis, the molecular mechanism of input, viral replication and immunological pathways, before the successful identification of targeted therapies. Although some drugs, such as corticosteroids and tocilizumab, seem to have a beneficial effect, the selection of the patient, the timing of administration and the most appropriate therapeutic schemes are the key points that need to be clarified. Other drugs are used in combination and in variable ways with uncertain efficacy and without definitive guidelines. In addition to the scarcity of evidence on the effectiveness of the various therapeutic options, the rush to publish the data as soon as possible has created confusion and embarrassment, as happened in the case of the study on hydroxychloroquine, which was later withdrawn.

Regarding mechanical ventilation and HFNC, to date no data about which is the best strategy in COVID-19 is available. At the moment, the best approach may be to ventilate at the best of the clinicians' knowledge and possibilities, also in relation with available resources. Using NIV or HFNC, in combination with drugs with evidence of efficacy such as dexamethasone or TCZ, may currently be the best strategy, pending the arrival of better options.

What will represent the real solution to the enormous problem that is occurring in the world is the identification of a safe vaccine, and in this regard preliminary report of the great effort put in place seem reassuring about efficacy and safety $[114,115]$. To date phase 3 clinical trials are still ongoing, future results will give us the ability to draw conclusion as to whether the developed vaccine will give prolonged protection to SARS-CoV-2 infection.

\author{
Abbreviations \\ SARS-CoV-2: Severe Acute Respiratory Syndrome Coronavirus 2; \\ COVID-19: Coronavirus Disease of 2019; \\ RCTs: randomized clinical trials; \\ ACE2: $\quad$ angiotensin-converting enzyme 2; \\ IFNs: interferons; \\ NK cells: natural killer cells; \\ APCs: antigen-presenting cells; \\ $\mathrm{PaO}_{2} / \mathrm{FiO}_{2}$ : Ratio of arterial oxygen partial pressure to fractional \\ inspired oxygen; \\ CRP: $\quad$ C-reactive protein; \\ LDH: $\quad$ lactate dehydrogenase; \\ CPK: $\quad$ creatine phosphokinase; \\ PCT: procalcitonin; \\ DIC: disseminated intravascular coagulation; \\ VTE: $\quad$ venous thromboembolism; \\ CT: computed tomography; \\ GGO: $\quad$ ground glass opacities; \\ OP: $\quad$ organizing pneumonia; \\ HIV: $\quad$ Human immunodeficiency virus; \\ NIAID: US National Institute of Allergy and Infectious \\ Diseases; \\ ARDS: $\quad$ acute respiratory distress syndrome; \\ TCZ: tocilizumab; \\ mAb: monoclonal antibody; \\ (IL)- 6: $\quad$ Interleukin 6; \\ RA: rheumatoid arthritis; \\ TRALI: $\quad$ transfusion-related acute lung injury; \\ PEEP: $\quad$ positive end-expiratory pressure; \\ VA/Q: $\quad$ ventilation-to-perfusion ratio; \\ NPPV: non-invasive positive pressure ventilation; \\ CPAP: $\quad$ continuous positive airway pressure; \\ ICU: intensive care unit; \\ NIV: $\quad$ non-invasive ventilation; \\ SILI: $\quad$ self-induced lung injury; \\ ECMO: extra-corporeal membrane oxygenation; \\ HFNC: $\quad$ high flow nasal cannula; \\ ARF: $\quad$ acute respiratory failure; \\ MSCs: mesenchymal stem cells.
}

\section{References}

1. Zhang Y-Z, Holmes EC. A Genomic perspective on the origin and emergence of SARS-CoV-2. Cell 2020;181:223-7.

2. Corman VM, Muth D, Niemeyer D, Drosten C. Hosts and sources of endemic human coronaviruses. Adv Virus Res. 2018; 100:163-188.

3. van Regenmortel MHV, Mahy BWJ. Emerging issues in virus taxonomy. Emerg Infect Dis 2004;10:8-13.

4. Schoeman D, Fielding BC. Coronavirus envelope protein: current knowledge. Virol J 2019;16:69.

5. WHO. Coronavirus Disease 2019. Accessed: June 12, 2020. Available from: https://www.who.int/emergencies/diseases/ novel-coronavirus-2019/events-as-they-happen

6. Mehta P, McAuley DF, Brown M, Sanchez E, Tattersall RS, Manson JJ. COVID-19: consider cytokine storm syndromes and immunosuppression. Lancet 2020;395:1033-4.

7. Chinese Clinical Trials. Accessed: July 14, 2020. Available from: http://www.chictr.org.cn/abouten.aspx

8. Andersen KG, Rambaut A, Lipkin WI, Holmes EC, Garry RF. The proximal origin of SARS-CoV-2. Nat Med 2020;26:450-2.

9. Shereen MA, Khan S, Kazmi A, Bashir N, Siddique R. COVID19 infection: Origin, transmission, and characteristics of human 
coronaviruses. J Adv Res 2020; 24:91-8.

10. Wan Y, Shang J, Graham R, Baric RS, Li F. Receptor recognition by the novel Coronavirus from Wuhan: an analysis based on decade-long structural studies of SARS Coronavirus. J Virol 2020;94:e00127-20.

11. Gralinski LE, Menachery VD. Return of the Coronavirus: 2019nCoV. Viruses 2020;12:135.

12. Ding Y, He L, Zhang Q, Che X, Hou J, Wang H, Shen H, et al. Organ distribution of severe acute respiratory syndrome (SARS) associated coronavirus (SARS-CoV) in SARS patients: implications for pathogenesis and virus transmission pathways. J Pathol 2004;203:622-30.

13. Lu R, Zhao X, Li J, Niu P, Yang B, Wu H, et al. Genomic characterisation and epidemiology of 2019 novel coronavirus: implications for virus origins and receptor binding. Lancet 2020;395:565-74.

14. Xu Z, Shi L, Wang Y, Zhang J, Huang L, Zhang C, et al. Pathological findings of COVID-19 associated with acute respiratory distress syndrome. Lancet Respir Med 2020;8:420-2.

15. Tian S, Hu W, Niu L, Liu H, Xu H, Xiao S-Y. Pulmonary pathology of early-phase 2019 novel Coronavirus (COVID-19) pneumonia in two patients with lung cancer. J Thorac Oncol $2020 ; 15: 700-4$.

16. Varga Z, Flammer AJ, Steiger P, Haberecker M, Andermatt R, Zinkernagel AS, et al. Endothelial cell infection and endothelitis in COVID-19. Lancet 2020;395:1417-8.

17. Guan W, Ni Z, Hu Y, Liang WH, Ou CQ, He JX, Liu L, et al. Clinical characteristics of Coronavirus Disease 2019 in China. N Engl J Med 2020;382):1708-20.

18. van Erp EA, Luytjes W, Ferwerda G, van Kasteren PB. Fc-mediated antibody effector functions during respiratory syncytial virus infection and disease. Front Immunol 2019;10: 548.

19. Bernstein KE, Khan Z, Giani JF, Cao D-Y, Bernstein EA, Shen $\mathrm{XZ}$. Angiotensin-converting enzyme in innate and adaptive immunity. Nat Rev Nephro. 2018;14:325-36.

20. Demers KR, Reuter MA, Betts MR. CD8 + T-cell effector function and transcriptional regulation during HIV pathogenesis. Immunol Rev 2013;254:190-206.

21. Thevarajan I, Nguyen THO, Koutsakos M, Druce J, Caly L, van de Sandt CE, et al. Breadth of concomitant immune responses prior to patient recovery: a case report of non-severe COVID-19. Nat Med 2020;26:453-5.

22. Prompetchara E, Ketloy C PT. Immune responses in COVID-19 and potential vaccines: Lessons learned from SARS and MERS epidemic. Asian Pacific J Allergy Immunol 2020; 38:1-9.

23. Channappanavar R, Zhao J, Perlman S. T cell-mediated immune response to respiratory coronaviruses. Immunol Res 2014;59:118-28.

24. Tian S, Xiong Y, Liu H, Niu L, Guo J, Liao M, et al. Pathological study of the 2019 novel coronavirus disease (COVID-19) through postmortem core biopsies. Mod Pathol 2020;33:100714.

25. Qin C, Zhou L, Hu Z, Zhang S, Yang S, Tao Y, et al. Dysregulation of immune response in patients with Coronavirus 2019 (COVID-19) in Wuhan, China. Clin Infect Dis 2020;71:762-8.

26. Huang C, Wang Y, Li X, Ren L, Zhao J, Hu Y, et al. Clinical features of patients infected with 2019 novel coronavirus in Wuhan, China. Lancet. 2020;395:497-506.

27. Zhang Y, Xiao M, Zhang S, Xia P, Cao W, Jiang W, et al. Coagulopathy and antiphospholipid antibodies in patients with Covid-19. N Engl J Med 2020;382:e38.

28. Chan JFW, Yuan S, Kok KH, To KK, Chu H, Yang J, et al. A familial cluster of pneumonia associated with the 2019 novel coronavirus indicating person-to-person transmission: a study of a family cluster. Lancet 2020;395:514-23.
29. Butowt R, von Bartheld CS. Anosmia in COVID-19: Underlying mechanisms and assessment of an olfactory route to brain infection. Neuroscientist 2020. doi: 10.1177/1073858 420956905

30. WHO. Clinical management of COVID-19 - Interim Guidance. Accessed October 15, 2020. Available from: www.who.int/publications/i/item/clinical-management-of-covid-19

31. Wu Z, McGoogan JM. Characteristics of and important lessons from the Coronavirus disease 2019 (COVID-19) outbreak in China. JAMA 2020;323):1239.

32. National Health Commission of the People's Republic of China. Guideline for the diagnosis and treatment of COVID-19 infections (version 1-8). 2020. Accessed October 15, 2020. Available from: http://regional.chinadaily.com.cn/

33. Zhou F, Yu T, Du R, Fan G, Liu Y, Liu Z, et al. Clinical course and risk factors for mortality of adult inpatients with COVID-19 in Wuhan, China: a retrospective cohort study. Lancet 2020;395:1054-62.

34. Iba T, Levy JH, Warkentin TE, Thachil J, Poll T, Levi M. Diagnosis and management of sepsis-induced coagulopathy and disseminated intravascular coagulation. J Thromb Haemost 2019;17:1989-94.

35. Luo W, Yu H, Gou J, Li X, Sun Y, Li J, Liu L. Clinical pathology of critical patient with novel Coronavirus pneumonia (COVID19). Preprints 2020;2020020407. Available from: https:/www.preprints.org/manuscript/202002.0407/v1

36. Kanne JP, Little BP, Chung JH, Elicker BM, Ketai LH. Essentials for radiologists on COVID-19: An update Radiology Scientific Expert Panel. Radiology 2020;296: E1134.

37. Ye Z, Zhang Y, Wang Y, Huang Z, Song B. Chest CT manifestations of new coronavirus disease 2019 (COVID-19): a pictorial review. Eur Radiol 2020;1-9.

38. Koo HJ, Lim S, Choe J, Choi SH, Sung H, Do KH. Radiographic and CT features of viral pneumonia. Radio Graphics 2018;38:719-39.

39. Maffessanti M, Dalpiaz G. Diffuse lung diseases. Milan: Springer Verlag; 2006.

40. Waseda Y, Johkoh T, Egashira R, Sumikawa H, Saeki K, Watanabe S, et al. Antisynthetase syndrome: Pulmonary computed tomography findings of adult patients with antibodies to aminoacyl-tRNA synthetases. Eur J Radiol 2016;85:1421-6.

41. Stower H. Lopinavir-ritonavir in severe COVID-19. Nat Med 2020;26:465.

42. Wang M, Cao R, Zhang L, Yang X, Liu J, Xu M, et al. Remdesivir and chloroquine effectively inhibit the recently emerged novel coronavirus $(2019-\mathrm{nCoV})$ in vitro. Cell Res 2020;30:269-71.

43. Du Y, Chen X. Favipiravir: Pharmacokinetics and concerns about clinical trials for 2019-nCoV infection. Clin Pharmacol Ther 2020;108:242-7.

44. Lu CC, Chen M-Y, Chang YL. Potential therapeutic agents against COVID-19. J Chinese Med Assoc 2020;83:534-6.

45. De Clercq E. New nucleoside analogues for the treatment of hemorrhagic fever virus infections. Chem Asian $\mathrm{J}$ 2019;14:3962-8.

46. Li G, De Clercq E. Therapeutic options for the 2019 novel coronavirus (2019-nCoV). Nat Rev Drug Discov 2020;19: 149-50.

47. de Wit E, Feldmann F, Cronin J, Jordan R, Okumura A, Thomas T, et al. Prophylactic and therapeutic remdesivir (GS-5734) treatment in the rhesus macaque model of MERS-CoV infection. Proc Natl Acad Sci USA 2020;117:6771-6.

48. Shen C, Wang Z, Zhao F, Yang Y, Li J, Yuan J, Wang F, et al. Treatment of 5 critically ill patients with COVID-19 with convalescent plasma. JAMA 2020;323:1582.

49. Agostini ML, Andres EL, Sims AC, Graham RL, Sheahan TP, 
$\mathrm{Lu} \mathrm{X}$, et al. Coronavirus susceptibility to the antiviral remdesivir (GS-5734) is mediated by the viral polymerase and the proofreading exoribonuclease. MBio 2018;9. doi: 10.1128/ mBio.00221-18

50. Ferner RE, Aronson JK. Remdesivir in covid-19. BMJ 2020;369:m1610.

51. BBC News [Internet]. Remdesivir: Drug has "clear-cut" power to fight coronavirus. Available from: https://www. bbc.com/news/health-52478783

52. Beigel JH, Tomashek KM, Dodd LE, Mehta AK, et al. Remdesivir for the treatment of Covid-19 - Final report. N Engl J Med 2020. doi: 10.1056/NEJMoa2007764

53. WHO Solidarity trial consortium, Pan H, Peto R, Abdool K, Quarraisha A, Alejandria M, et al. Repurposed antiviral drugs for COVID-19; interim WHO SOLIDARITY trial results. medRxiv 2020. doi: 10.1101/2020.10.15.20209817

54. Chu CM. Role of lopinavir/ritonavir in the treatment of SARS: initial virological and clinical findings. Thorax 2004;59:252-6.

55. Zumla A, Chan JFW, Azhar EI, Hui DSC, Yuen K-Y. Coronaviruses - drug discovery and therapeutic options. Nat Rev Drug Discov 2016;15:327-47.

56. Cao B, Wang Y, Wen D, Liu W, Wang J, Fan G, et al. A trial of lopinavir-ritonavir in adults hospitalized with severe Covid-19. N Engl J Med.2020;382:1787-99.

57. Chow EJ, Doyle JD, Uyeki TM. Influenza virus-related critical illness: prevention, diagnosis, treatment. Crit Care 2019; 23:214.

58. Wang D, Hu B, Hu C, Zhu F, Liu X, Zhang J, et al. Clinical characteristics of 138 hospitalized patients with 2019 Novel Coronavirus-infected pneumonia in Wuhan, China. JAMA 2020;323:1061.

59. Frisk-Holmberg M, Bergqvist Y, Englund U. Chloroquine intoxication. Br J Clin Pharmacol1983;15:502-3.

60. Chauhan A, Tikoo A. The enigma of the clandestine association between chloroquine and HIV-1 infection. HIV Med 2015;16:585-90.

61. Helal GK, Gad MA, Abd-Ellah MF, Eid MS. Hydroxychloroquine augments early virological response to pegylated interferon plus ribavirin in genotype-4 chronic hepatitis C patients. J Med Virol 2016;88:2170-8.

62. Mehra MR, Desai SS, Ruschitzka F, Patel AN. RETRACTED: Hydroxychloroquine or chloroquine with or without a macrolide for treatment of COVID-19: a multinational registry analysis. Lancet 2020. doi: 10.1016/S0140-6736(20) 31180-6

63. Mehra MR, RuschitzkRa, Patel AN. Retraction Hydroxychloroquine or chloroquine with or without a macrolide for treatment of COVID-19: A multinational registry analysis. Lancet 2020. doi: 10.1016/S0140-6736(20) 31324-6

64. Simmons G, Bertram S, Glowacka I, Glowacka I, Steffen I, Chaipan C, et al. Different host cell proteases activate the SARS-coronavirus spike-protein for cell-cell and virus-cell fusion. Virology 2011;413:265-74.

65. Gao J, Tian Z, Yang X. Breakthrough: Chloroquine phosphate has shown apparent efficacy in treatment of COVID-19 associated pneumonia in clinical studies. Biosci Trends 2020;14: 72-3.

66. Gautret P, Lagier J-C, Parola P, Hoang VT, Meddeb L, Mailhe $\mathrm{M}$, et al. Hydroxychloroquine and azithromycin as a treatment of COVID-19: results of an open-label non-randomized clinical trial. Int J Antimicrob Agents 2020;105949.

67. Molina JM, Delaugerre C, Le Goff J, Mela-Lima B, Ponscarme $\mathrm{D}$, Goldwirt L, et al. No evidence of rapid antiviral clearance or clinical benefit with the combination of hydroxychloroquine and azithromycin in patients with severe COVID-19 infection. Med Mal Infect 2020;50:384.

68. Mehra MR, Desai SS, Ruschitzka F, Patel AN. RETRACTED: Hydroxychloroquine or chloroquine with or without a macrolide for treatment of COVID-19: a multinational registry analysis.
Lancet 2020:S0140-6736(20)31180-6.

69. Recovery Trial [Internet]. Hydroxychloroquine results Accessed: August 9, 2020. Available from: https://www. recoverytrial.net/results/hydroxychloroquine-results

70. Wu C, Chen X, Cai Y, Xia J, Zhou X, Xu S, et al. Risk factors associated with acute respiratory distress syndrome and death in patients with Coronavirus disease 2019 pneumonia in Wuhan, China. JAMA Intern Med 2020; 200994.

71. Chen R, Tang X, Tan S, Liang BL, Wan ZY, Fang JQ, et al. Treatment of severe acute respiratory syndrome with glucosteroids. Chest 2006;12):1441-52.

72. Zhao JP, Hu Y, Du RH, Chen ZS, Jin Y, Zhou M, et al. [Expert consensus on the use of corticosteroid in patients with 2019nCoV pneumonia].[Article in Chinese]. Zhonghua Jie $\mathrm{He} \mathrm{He} \mathrm{Hu}$ Xi Za Zhi 2020. doi: 10.3760/cma.j.issn.1001-0939.2020.0007

73. Ma Q, Qi D, Deng XY, Yuan GD, Tian WG, Cui Y, et al. Corticosteroid therapy for patients with severe novel Coronavirus disease 2019. Eur Rev Med Pharmacol Sci 2020;24:8194-201.

74. Russell CD, Millar JE, Baillie JK. Clinical evidence does not support corticosteroid treatment for 2019-nCoV lung injury. Lancet 2020;395:473-5.

75. RECOVERY Collaborative Group, Horby P, Wei SL, Emberson JR, Mafham M, Bell JL, et al. Dexamethasone in hospitalized patients with Covid-19 - Preliminary report. N Engl J Med 2020. doi: 10.1056/NEJMoa2021436

76. Kaneko Y, Kato M, Tanaka Y, Inoo M, Kobayashi-Haraoka H, Amano K, et al. Tocilizumab discontinuation after attaining remission in patients with rheumatoid arthritis who were treated with tocilizumab alone or in combination with methotrexate: results from a prospective randomised controlled study (the second year of the SURPRISE study). Ann Rheum Dis 2018;77:1268-75.

77. Toniati P, Piva S, Cattalini M, Garrafa E, Regola F, Castelli F, et al. Tocilizumab for the treatment of severe COVID-19 pneumonia with hyperinflammatory syndrome and acute respiratory failure: A single center study of 100 patients in Brescia, Italy. Autoimmun Rev 2020;19:102568.

78. Menzella F, Fontana M, Salvarani C, Massari M, Ruggiero P, Scelfo C, et al. Efficacy of tocilizumab in patients with COVID19 ARDS undergoing noninvasive ventilation. Crit Care 2020;24:589.

79. Scott LJ. Sarilumab: First global approval. Drugs 2017;77: 70512.

80. Lamb YN, Deeks ED. Sarilumab: A review in moderate to severe rheumatoid arthritis. Drugs 2018;78:929-40.

81. Schett G, Manger B, Simon D, Caporali R. COVID-19 revisiting pathways inflammatory diseases of arthritis. Nat Rev Rheumatol 2020;16:465-70.

82. Marí Sáez A, Ronse M, Delamou A, Haba N, Bigey F, van Griensven J, et al. The plasma mobile, 'A gift from heaven': The impact of health technology transfer on trial perceptions and expectations during the Ebola-Tx Trial, Conakry. PLoS Negl Trop Dis 2020;14:e0008206.

83. Li L, Zhang W, Hu Y, Tong X, Zheng S, Yang J, et al. Effect of convalescent plasma therapy on time to clinical improvement in patients with severe and life-threatening COVID-19: a randomized clinical trial. JAMA 2020;324:1-11.

84. Perotti C, Baldanti F, Bruno R, Del Fante C, Seminari E, Casari $\mathrm{S}$, et al. Mortality reduction in 46 severe Covid-19 patients treated with hyperimmune plasma. A proof of concept single arm multicenter trial. Haematologica 2020. doi: 10.3324/haematol.2020.261784

85. Mucha SR, Quraishy N. Convalescent plasma for COVID-19. Cleve Clin J Med 2020. doi: 10.3949/ccjm.87a.ccc056

86. Gattinoni L, Chiumello D, Caironi P, Busana M, Romitti F, 
Brazzi L, et al. COVID-19 pneumonia: different respiratory treatments for different phenotypes? Intensive Care Med 2020;46:1099-102.

87. Gattinoni L, Coppola S, Cressoni M, Busana M, Rossi S, Chiumello D. Covid-19 does not lead to a "typical" acute respiratory distress syndrome. Am J Respir Crit Care Med 2020;201:1299-300.

88. Tonelli R, Fantini R, Tabbì L, Castaniere I, Pisani L, Pellegrino $\mathrm{MR}$, et al. Inspiratory effort assessment by esophageal manometry early predicts noninvasive ventilation outcome in de novo respiratory failure. A pilot study. Am J Respir Crit Care Med 2020;202:558-67.

89. Allen K, Hoffman L. Enteral nutrition in the mechanically ventilated patient. Nutr Clin Pract 2019;34:540-57.

90. Takasaki Y, Kido T, Semba K. Dexmedetomidine facilitates induction of noninvasive positive pressure ventilation for acute respiratory failure in patients with severe asthma. J Anesth 2009;23:147-50.

91. Devlin JW, Nava S, Fong JJ, Bahhady I, Hill NS. Survey of sedation practices during noninvasive positive-pressure ventilation to treat acute respiratory failure. Crit Care Med 2007;35: 2298-E4.

92. Muriel A, Peñuelas O, Frutos-Vivar F, Arroliga AC, Abraira V, Thille AW, et al. Impact of sedation and analgesia during noninvasive positive pressure ventilation on outcome: a marginal structural model causal analysis. Intensive Care Med 2015;41:1586-600.

93. Chad T, Sampson C. Prone positioning in conscious patients on medical wards: A review of the evidence and its relevance to patients with COVID-19 infection. Clin Med (Lond) 2020;20:e97-103.

94. Tang KQ, Yang SL, Zhang B, Liu HX, Ye DY, Zhang HZ, et al. Ultrasonic monitoring in the assessment of pulmonary recruitment and the best positive end-expiratory pressure. Medicine (Baltimore) 2017;96:e8168.

95. Poston JT, Patel BK, Davis AM. Management of critically ill adults with COVID-19. JAMA 2020;323:1839-41.

96. Ikuyama Y, Wada Y, Tateishi K, Kitaguchi Y, Yasuo M, Ushiki A, et al. Successful recovery from critical COVID-19 pneumonia with extracorporeal membrane oxygenation: A case report. Respir Med Case Rep 2020;30:101113.

97. Parke RL, McGuinness SP. Pressures delivered by nasal high flow oxygen during all phases of the respiratory cycle. Respir Care 2013;58:1621-4.

98. Franco C, Facciolongo N, Tonelli R, Dongilli R, Vianello A, Pisani L, et al. Feasibility and clinical impact of out-of-ICU noninvasive respiratory support in patients with COVID-19 related pneumonia. Eur Respir J 2020:2002130.

99. Rochwerg B, Granton D, Wang DX, Helviz Y, Einav S, Frat JP, et al. High flow nasal cannula compared with conventional oxygen therapy for acute hypoxemic respiratory failure: a systematic review and meta-analysis. Intensive Care Med 2019;45:56372.

100. Geng S, Mei Q, Zhu C, Yang T, Yang Y, Fang X, et al. High flow nasal cannula is a good treatment option for COVID-19. Heart Lung 2020;49:444-5.

101. Karamouzos V, Fligou F, Gogos C, Velissaris D. High flow nasal cannula oxygen therapy in adults with COVID-19 respiratory failure. A case report. Monaldi Arch Chest Dis 2020;90:1323. doi: 10.4081/monaldi.2020.1323

102. Hammer Q, Ruckert T, Romagnani C. Natural killer cell specificity for viral infections. Nat Immunol 2018;19:800-8.

103. Seeking Alpha [Internet]. Sorrento and Celularity to initiate emergency allogeneic natural killer (NK) cell therapy development for coronavirus infection. Accessed: August 9, 2020. Available from: https://seekingalpha.com/pr/17762358-sorrento-and-celularity-to-initiate-emergency-allogeneic-naturalkiller-nk-cell-therapy

104. Ortiz LA, Dutreil M, Fattman C, Pandey AC, Torres G, Go K, et al. Interleukin 1 receptor antagonist mediates the antiinflammatory and antifibrotic effect of mesenchymal stem cells during lung injury. Proc Natl Acad Sci USA 2007;104:11002-7.

105. Gupta N, Su X, Popov B, Lee JW, Serikov V, Matthay MA. Intrapulmonary delivery of bone marrow-derived mesenchymal stem cells improves survival and attenuates endotoxin-induced acute lung injury in mice. J Immunol 2007;179:1855-63.

106. Moodley Y, Atienza D, Manuelpillai U, Samuel CS, Tchongue J, Ilancheran S, et al. Human umbilical cord mesenchymal stem cells reduce fibrosis of bleomycin-induced lung injury. Am J Pathol 2009;175:303-13.

107. Matthay MA, Goolaerts A, Howard JP, Lee JW. Mesenchymal stem cells for acute lung injury: preclinical evidence. Crit Care Med 2010;38:S569-73.

108. Kumamoto M, Nishiwaki T, Matsuo N, Kimura H, Matsushima $\mathrm{K}$. Minimally cultured bone marrow mesenchymal stem cells ameliorate fibrotic lung in- jury. Eur Respir J 2009;34:740-8.

109. Quan L, Zhang Y, Crielaard BJ, Dusad A, Lele SM, Rijcken CJF, et al. Nanomedicines for inflammatory arthritis: head-to-head comparison of glucocorticoid-containing polymers, micelles, and liposomes. ACS Nano 2014;8:458-66.

110. Banciu M, Metselaar JM, Schiffelers RM, Storm G. Liposomal glucocorticoids as tumor-targeted anti-angiogenic nanomedicine in B16 melanoma-bearing mice. J Steroid Biochem Mol Biol 2008;111:101-10.

111. Crielaard BJ, Lammers T, Morgan ME, Chaabane L, Carboni S, Greco B, et al. Macrophages and liposomes in inflammatory disease: friends or foes? Int J Pharm 2011;416:499-506.

112. Bartneck M, Scheyda KM, Warzecha KT, Rizzo LY, Hittatiya K, Luedde T, et al. Fluorescent cell-traceable dexamethasone-loaded liposomes for the treatment of inflammatory liver diseases. Biomaterials 2015;37:367-82.

113. Lammers T, Sofias AM, van der Meel R, Schiffelers R, Storm G, Tacke F, et al. Dexamethasone nanomedicines for COVID-19. Nat Nanotechnol.2020;15:622-4.

114. Jackson LA, Anderson EJ, Rouphael NG, Roberts PC, Makhene $\mathrm{M}$, Coler RN, et al. An mRNA Vaccine against SARS-CoV-2 Preliminary Report. N Engl J Med 2020. doi: 10.1056/ NEJ Moa2022483

115. National Institutes of Health [Internet]. NIH-Moderna investigational COVID-19 vaccine shows promise in mouse studies. Accessed August 9, 2020. https:/www.nih.gov/news-events/ news-releases/nih-moderna-investigational-covid-19-vaccineshows-promise-mouse-studies

Received for publication: 9 August 2020. Accepted for publication: 19 October 2020.

This work is licensed under a Creative Commons Attribution-NonCommercial 4.0 International License (CC BY-NC 4.0).

(C) Copyright: the Author(s), 2020

Licensee PAGEPress, Italy

Multidisciplinary Respiratory Medicine 2020; 15:708

doi:10.4081/mrm.2020.708 